To be presented at the STAIF Conference on Space Exploration Technology, Albuquerque NM, Feb. 11-15, 2001

\title{
Exploring Venus by Solar Airplane
}

\author{
Geoffrey A. Landis \\ NASA John Glenn Research Center, mailstop 302-1, 21000 Brookpark Road, Cleveland, OH 44135 \\ (216) 433-2238e-mail: geoffrey.landis@grc.nasa.gov
}

\begin{abstract}
A solar-powered airplane is proposed to explore the atmospheric environment of Venus. Venus has several advantages for a solar airplane. At the top of the cloud level, the solar intensity is comparable to or greater than terrestrial solar intensities. The Earthlike atmospheric pressure means that the power required for flight is lower for Venus than that of Mars, and the slow rotation of Venus allows an airplane to be designed for continuous sunlight, with no energy storage needed for night-time flight. These factors mean that Venus is perhaps the easiest planet in the solar system for flight of a long-duration solar airplane.
\end{abstract}

\section{INTRODUCTION}

The surface of Venus is an extremely hostile environment, but for exploration at roughly the level of the cloud tops, the environment of Venus is comparatively benign. Table 1 shows some of the relevant parameters of Venus (Hunten et al., 1983; Bougher, Hunten, and Phillips 1997). From an altitude of approximately $45 \mathrm{~km}$, where the pressure is two bars (twice the Earth surface pressure), to approximately $60 \mathrm{~km}$, where the pressure is 0.2 bars, terrestrial airplane experience can be easily applied to a Venus airplane design. The atmospheric temperature is roughly $80^{\circ} \mathrm{C}$ at $45 \mathrm{~km}$, decreasing to $-35^{\circ} \mathrm{C}$ at $60 \mathrm{~km}$. At the cloud level, the environment of Venus is an easy one in which to make an airplane fly.

A solar-powered airplane is proposed to explore the atmospheric environment of Venus.

Venus has several advantages for a solar airplane. The exoatmospheric solar intensity is $2.6 \mathrm{~kW} / \mathrm{m}^{2}$ (nearly double the value of $1.37 \mathrm{~kW} / \mathrm{m}^{2}$ at the orbit of Earth). At the cloud level, this solar intensity is somewhat attenuated by atmospheric opacity, but at the higher altitudes the solar intensity is comparable to, or even greater than, terrestrial solar intensities. The surface gravity of Venus is $10 \%$ lower than Earth's. An additional design factor is the high albedo of Venus. According to measurements by the 1978 Pioneer Venus probe, for example (Fimmel, Colin, and Burgess 1983), at an altitude of $60 \mathrm{~km}$ the reflected (upward) solar intensity is equal to $90 \%$ of the downward solar intensity, allowing both the top and bottom surfaces of a solar airplane to produce power.

The Earthlike atmospheric pressure means that the power required for flight is lower for Venus than, for example, Mars, where airplane flight is difficult due to the low density atmosphere.

Finally, the planet Venus allows the possibility of designing an airplane for continuous sunlight, thus eliminating the requirement for energy storage during night-time flight. These factors mean that Venus is perhaps the easiest planet in the solar system for flight of a long-duration solar airplane.

\section{DESIGN FACTORS FOR VENUS AIRPLANE}

The extraordinarily slow rotation rate of Venus results in a very long solar day, of duration 117 (Earth) days. This means that the ground speed required for an airplane to remain at the subsolar point is extremely slow, only 13.4 $\mathrm{km} / \mathrm{hr}$ at the equator.

This is a preprint or reprint of a paper intended for presentation at a conference. Because changes may be made before formal publication, this is made available with the understanding that it will not be cited or reproduced without the permission of the author. 
TABLE 1. Basic Information about Venus

\begin{tabular}{|c|c|c|}
\hline \multicolumn{2}{|l|}{ Distance from sun (average) } & 108 million $\mathrm{km}(0.72 \mathrm{AU})$ \\
\hline \multicolumn{2}{|l|}{ Orbital period } & 224.7 (Earth) days \\
\hline \multicolumn{2}{|l|}{ Surface Gravity } & $8.87 \mathrm{~m} / \mathrm{sec}^{2}(90.7 \%$ of Earth $)$ \\
\hline \multicolumn{2}{|l|}{$\begin{array}{l}\text { Synodic period } \\
\text { (time between launch windows) }\end{array}$} & $\begin{array}{l}583.9 \text { days } \\
\text { (1.6 years) } \\
\end{array}$ \\
\hline \multicolumn{2}{|l|}{ Solar day } & 117 days (retrograde) \\
\hline \multicolumn{2}{|l|}{ Solar Constant } & $2.62 \mathrm{~kW} / \mathrm{m}^{2}$ \\
\hline \multicolumn{2}{|l|}{ Albedo } & 0.8 \\
\hline \multicolumn{2}{|l|}{ Atmospheric pressure at surface } & 90 bar \\
\hline \multicolumn{2}{|l|}{ Pressure decrease with altitude } & $P=P_{0} \exp [-h / 15.8 \mathrm{~km}]$ \\
\hline \multicolumn{2}{|c|}{ Temperature at surface } & $462 \pm 2{ }^{\circ} \mathrm{C}$ \\
\hline \multicolumn{2}{|c|}{ Temperature decrease with altitude } & $8^{\circ} \mathrm{C}$ per kilometer \\
\hline \multicolumn{2}{|c|}{ Atmospheric composition } & $96.5 \% \mathrm{CO}_{2}, 3.5 \% \mathrm{~N}_{2}$ \\
\hline $\begin{array}{l}\text { Wind velocity as function } \\
\text { of altitude (Eastward) } \\
\text { (note: depends on latitude) }\end{array}$ & $\begin{array}{l}45 \mathrm{~km} \\
53 \mathrm{~km} \\
60 \mathrm{~km} \\
\end{array}$ & $\begin{array}{l}44 \mathrm{~m} / \mathrm{sec} \\
65 \mathrm{~m} / \mathrm{sec}^{*} \\
100 \mathrm{~m} / \mathrm{sec} \\
\end{array}$ \\
\hline
\end{tabular}

Unfortunately, at the cloud-top altitudes of interest to airplane exploration, the wind velocities are considerably higher than the actual rotation rate of the planet, circling the planet at the cloud-top level in a period of 4 to 5 days. At an altitude of $45 \mathrm{~km}$ above the surface the wind speed is about $45 \mathrm{~m} / \mathrm{sec}(160 \mathrm{~km} / \mathrm{h})$, increasing to 100 meters per second $(360 \mathrm{~km} / \mathrm{hr})$ at $60 \mathrm{~km}$.

This puts engineering constraints on an airplane designed to remain in the sunlight. Three possible design approaches to keeping the airplane in constant sunlight are: design for an airspeed of $100 \mathrm{~m} / \mathrm{sec}$ speed; design to fly at lower altitudes where the wind speed is lower (but solar intensity is also less), or to operate at near-polar latitudes, where the wind speeds are reduced (but the sun angle is high). Each of these approaches drives the design toward a different optimum configuration.

An environmental hazard unique to the Venus environment is the chemical reactivity of the atmosphere. The primary component of the Venus clouds is droplets of sulfuric acid. This will require that all exposed surfaces of the airplane be coated by materials impervious to chemical attack; for example, the solar arrays must be encapsulated with no exposed openings, e.g., by a combination of glass and Teflon coatings. However, sulfuric acid is a common industrial chemical, and the technology of dealing with it is well developed. With careful design, there is no reason why a solar airplane could not remain airborne in the Venus atmosphere indefinitely.

The proposed Venus airplane uses a folding-wing design to fit the solar airplane into an atmospheric-entry "aeroshell". Figure 1 shows one possible configuration for a folding-wing airplane, sized to fit inside the 1.2-meter diameter Pioneer-Venus "small probe" aeroshell. The wing folds in two places. The unusually wide chord of the wing is sized in order to maximize the solar array area.

After heat-shield separation, parachute deployment, and stabilization of descent, the airplane is unfolded and is dropped from the parachute at an altitude of $65-70 \mathrm{~km}$ above the surface. The airplane then slowly descends to the desired flying altitude and begins its observations.

\section{SCIENCE MISSION FOR A VENUS AIRPLANE}

There are a number of important science questions, which can be addressed by flying a probe at the cloud level of Venus. This is the altitude at which the largest fraction of solar energy is absorbed, so questions relating to understanding the greenhouse effect on Venus are best probed at this level. A Venus airplane could, for example, provide valuable "atmospheric truth" measurements to ground the general circulation models of planetary climates. Improved knowledge of the climate of Venus is critical not only to planetary science, but also to our understanding of our own planet Earth.

In addition, the Venus atmosphere holds significant scientific questions that have yet to be answered ( Bougher, Hunten, and Phillips 1997): what causes the superrotation of the atmosphere? What is the composition of the 
atmospheric ultraviolet absorber? What is the size, shape, and composition of the "mode-three" particles, which are the primary component (by mass) of cloud particles between the altitudes of $30-58 \mathrm{~km}$ ?

As a geology instrument, a long duration Venus airplane could be used to probe the surface by radar, giving an order of magnitude in resolution of ground features. This might be done by using the airplane as a receiver, using an orbital microwave transmitter.

An airplane would also be an ideal delivery vehicle to drop surface probes at geologically interesting locations, and to "sniff" for the chemical signature of the plumes from volcanic eruptions, to answer the now-open question of whether Venus currently has active volcanism.

Previous proposals for atmospheric probes of Venus have suggested the use of balloons. Balloons were used, for example, in the 1985 Russian "Vega" mission (Bougher, Hunten, and Phillips 1997). While a balloon must drift with the atmospheric motion, however, an airplane has the advantage of allowing considerable better control of position, allowing measurements above a specific location and at a range of altitudes.

Two or more airplanes can also be used to fly in formation, allowing measurement of the correlation of atmospheric properties as a function of altitude or position.

In addition to its scientific value, however, a significant benefit of the Venus airplane will be its "fun" factor. As the first airplane flown on another planet, it is certain to attract a lot of public attention. And the Venus airplane can serve to show the way to future exploration by solar airplanes on Mars, Jupiter, Satum, and Titan.

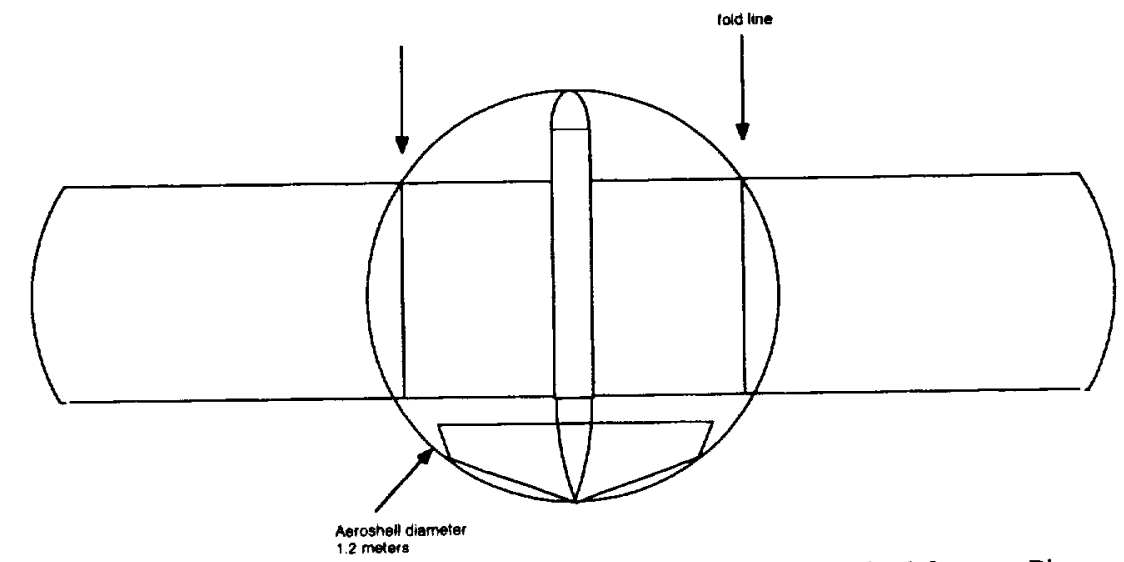

FIGURE 1. Schematic Showing Wing Fold for Venus Solar Airplane, Sized to Fold Into the 1.2-meter Pioneer Venus Small-probe Aeroshell.

\section{CONCLUSIONS}

With a thick atmosphere, gravity that is slightly less than that of Earth, high solar constant, and a slow rotation, at the cloud-level of the atmosphere of Venus flight is easy for a solar powered airplane. A solar powered airplane flying in the atmosphere of Venus could do significant scientific objectives, as well as demonstrating, for the first time, atmospheric flight on another planet.

\section{REFERENCES}

Bougher, S.W., Hunten, D.M., and Phillips, R.J., eds., Venus II: Geology, Geophysics, Atmosphere, and Solar Wind Environments, University of Arizona Press, Space Science Series, Tucson, AZ, 1997.

Fimmel, R.O., Colin, L., and Burgess, E., Pioneer Venus, NASA, Washington, DC., NASA SP-461, 1983.

Hunten, D.M., Colin, L., Donahue, T.M., and Moroz, V.I., eds., Venus, University of Arizona Press, Space Science Series, Tucson, AZ, 1983. 